\title{
Photolon $^{\mathrm{TM}}$ - Photosensitization induces apoptosis via ROS-mediated cross-talk between mitochondria and lysosomes
}

\author{
MOHAMED ALI-SEYED ${ }^{1,4}$, RAMASWAMY BHUVANESWARI ${ }^{1}$, KHEE CHEE SOO ${ }^{1}$ and MALINI OLIVO ${ }^{1,2,3}$ \\ ${ }^{1}$ Division of Medical Science, National Cancer Centre Singapore, 169610 Singapore; ${ }^{2}$ School of Physics, \\ National University of Ireland Galway, Galway, Ireland; ${ }^{3}$ Department of Pharmacy, National University of Singapore, \\ 117543 Singapore; ${ }^{4}$ Department of Biotechnology, School of Bioengineering, SRM University, \\ Kattankulathur-603203, Kancheepuram District, Tamilnadu, India
}

Received March 4, 2011; Accepted April 11, 2011

DOI: 10.3892/ijo.2011.1109

\begin{abstract}
The localization of photosensitizers in the subcellular compartments during photodynamic therapy (PDT) plays a major role in the cell destruction; therefore, the aim of this study was to investigate the intracellular localization of Chlorin e6-PVP (Photolon ${ }^{\mathrm{TM}}$ ) in malignant and normal cells. Our study involves the characterization of the structural determinants of subcellular localization of Photolon, and how subcellular localization affects the selective toxicity of Photolon towards tumor cells. Using confocal laser scanning microscopy (CLSM) and fluorescent organelle probes; we examined the subcellular localization of Photolon ${ }^{\mathrm{TM}}$ in the murine colon carcinoma CT-26 and normal fibroblast (NHLC) cells. Our results demonstrated that after 30 min of incubation, the distribution of Photolon was localized mainly in the cytoplasmic organelles including the mitochondria, lysosomes, Golgi apparatus, around the nuclear envelope and also in the nucleus but not in the endoplasmic reticulum whereas in NHLC cells, Photolon was found to be localized minimally only in the nucleus not in other organelles studied. The relationship between subcellular localization of Photolon and PDT-induced apoptosis was investigated. Apoptotic cell death was judged by the formation of known apoptotic hallmarks including, the phosphatidylserine externalization (PS), PARP cleavage, a substrate for caspase- 3 and the formation of apoptotic nuclei. At the irradiation dose of $1 \mathrm{~J} / \mathrm{cm}^{2}$, the percentage of apoptotic cells was $80 \%$, respectively. This study provided substantial evidence that Photolon preferentially localized in the subcellular organelles in the following order: nucleus, mitochondria, lysosomes and the Golgi apparatus and subsequent photodamage of the mitochondria and lysosomes played an important role in PDT-mediated apoptosis CT-26 cells. Our results based on the cytoplasmic organelles and
\end{abstract}

Correspondence to: Professor Malini Olivo, School of Physics, National University of Ireland Galway, University Road, Galway, Ireland

E-mail: malini.olivo@nuigalway.ie

Key words: Photolon $^{\mathrm{TM}}$, photosensitization, apoptosis, mitochondria, lysosomes the intranuclear localization extensively enhance the efficacy of PDT with appropriate photosensitizer and light dose and support the idea that PDT can contribute to elimination of malignant cells by inducing apoptosis, which is of physiological significance.

\section{Introduction}

The treatment of most cancers is still inadequate, despite steady progress. A major problem in the treatment of cancer is the specific targeting of anti-tumor drugs to these abnormal cells. Ideally, such a drug should act over short distances to minimize damage to healthy cells, and target subcellular compartments that have the highest sensitivity to the drug. Compared to current treatments including surgery, radiation and chemotherapy, photodynamic therapy (PDT) offers the advantage of an effective and selective method of destroying diseased tissues without damaging surrounding healthy tissues (1). PDT, a rapidly growing field in medicine, has been established as a useful treatment modality for some cancers by results from preclinical and clinical studies conducted world-wide in the last two and half decades (2) because of its low systemic toxicology and repeatable nature $(3,4)$. One of the aspects of anti-tumor effectiveness of PDT is related to the distribution of photosensitizing drugs. The incorporation and subcellular localization of photosensitizers are critical determinants of their efficiency.

Photosensitizers (Ps) are chromophores that generate reactive oxygen species (ROS) including singlet oxygen upon light irradiation. The Ps selectively localizes in malignant cells compared to normal tissues. The use of chlorin-type photosensitizers for the selective destruction of cancer cells has been known for several decades because of their high phototoxic potential and relatively strong absorption in the red region of the visible spectrum leading to destruction of diseased tissue in deeper tissue layers. Chlorin e6 (Ce6) is a naturally occurring chlorin derivative that has shown promise as a cancer therapeutic (5). The Ce6 molecule has been adapted to improve its clinical efficacy, and has decreased side effects compared to first generation photosensitizers from hematoporphyrin derivatives. Photolon ${ }^{\mathrm{TM}} /$ Fotolon $^{\mathrm{TM}}$ is a water-soluble photosensitizer; the conjugation of $\mathrm{Ce} 6$ to the hydrophilic polymer 


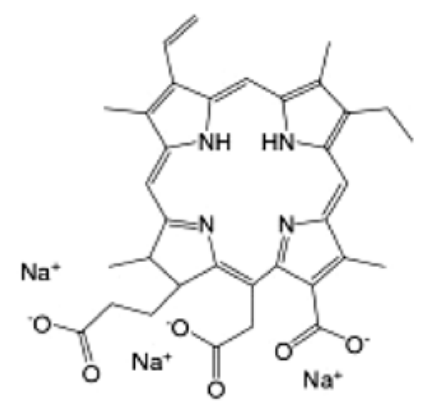

Chlorin e6

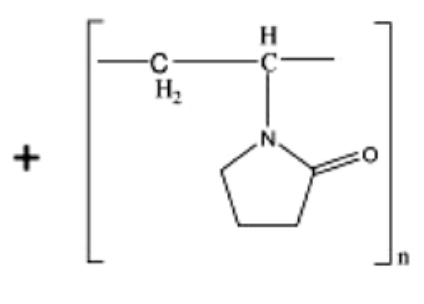

Polyvinylpyrrolidone
Figure 1. Chemical structure of the photosensitizer Photolon.

polyvinylpyrrolidone (PVP) making Photolon hydrophilic in nature (6-9). While lipophilic photosensitisers (e.g, lipophilic porphyrins) are preferentially taken up through the plasma membrane of the cell, hydrophilic photosensitisers tend to be taken up by pinocytosis (10), a form of endocytosis, where particles are taken in by the cell in endosomal vesicles which subsequently fuse with lysosomes (i.e., lysosomotropic delivery) to exerts its effects. Photosensitizers were classified according to their initial affinity for specific subcellular organelles in vitro and described by the consequences of each major localization site with regard to direct tumor cell kill $(11,12)$.

Multiple signaling cascades are concomitantly activated in cancer cells exposed to the photodynamic stress and depending on the subcellular localization of the damaging ROS, these signals are transduced into adaptive or cell death responses. Recent evidence indicates that PDT can kill cancer cells directly by the efficient induction of apoptotic as well as non-apoptotic cell death pathways. Although Photolon has clinical advantages and appears to be proficient in the killing of cancer cells in vivo (13), little is known regarding its specific subcellular organelles localization, and the consequences of each major localization site with regard to direct tumor cell kill or photobiological effects. In this study, an in vitro investigation using mouse colon cells (CT-26) was performed to determine a new photosensitizer Photolon-affinity for specific subcellular organelles and the mechanism of Photolon-induced cell death.

\section{Materials and methods}

Reagents. The following chemicals and reagents were obtained from the indicated companies: Chlorin e6-PVP (Photolon, structure shown in Fig. 1) was obtained from Orpegen Pharma $\mathrm{GmbH}$, Heidelberg, Germany and dissolved in $0.9 \%$ sodium chloride $(\mathrm{NaCl})$ at a stock concentration of $1 \mathrm{mg} / \mathrm{ml}$ and working dilutions were directly made in the tissue culture medium. Diode laser (Ceralas PDT 665, Biolitec); DMEM medium (in house preparation); fetal bovine serum (FBS, Gibco-BRL ${ }^{\circledR}$, Life Technologies Inc., Gaithersburg, MD, USA); mAb cytochrome $\mathrm{C} ; \mathrm{mAb}$ against PARP (Santa Cruz Biotechnology, Inc., Santa Cruz, CA, USA); mAb against GRASP65, $\mathrm{mAb}$ against actin (Sigma Chemical Industries, St. Louis, MO, USA) streptavidin-peroxidase (Gibco-BRL, Life Technologies Inc.); biotinylated horse anti-mouse $\operatorname{IgG}(\mathrm{H}+\mathrm{L})$ antibody (Vector Laboratories Inc., Burlingame, CA, USA); 3,3'- diaminebenzidine tetrahydrochloride (DAB, Sigma Chemical Industries); a TumorTACS ${ }^{\mathrm{TM}}$ In situ Apoptosis Detection Kit (Trevigen,Inc., Gaithersburg,MD,USA); 3,3'-dihexyloxacarbocyanine iodide $\left[\operatorname{DioC}_{6}(3)\right]$, MitoTracker Green, LysoTracker Green $^{\mathrm{TM}}$, TO-PRO 3 Iodide (Molecular Probes Inc., Eugene, OR, USA); mAb against GRASP65 a Golgi apparatus marker (Sigma); mAb-Calreticulin (endoplasmic reticulum marker). All the secondary antibodies were obtained from Vector Laboratories and Jackson ImmunoResearch.

Cell culture. The mouse colon cell line CT-26, human breast MCF-7, A453 were cultured in Dulbecco's modified Eagle's medium (DMEM; Gibco, Grand Island, NY, USA) and normal fibroblast cells (NHLC) was cultured in RPMI medium at $37^{\circ} \mathrm{C}$ in a humidified $5 \% \mathrm{CO}_{2}$ atmosphere. The medium was supplemented with $10 \%$ fetal bovine serum (Gibco), $100 \mathrm{U} / \mathrm{ml}$ penicillin, $100 \mu \mathrm{g} / \mathrm{ml}$ streptomycin and $2 \mathrm{mM}$ glutamine. The cells were maintained in exponential growth in monolayer cultures with regular medium changes.

Light irradiation. Six-well plates and chamber slides were used for irradiation, cells were incubated with Photolon $(10 \mu \mathrm{M})$ in complete medium $(<0.04 \%$ DMSO $)$ for $30 \mathrm{~min}$, then just prior to irradiation washed twice with phosphate buffer saline (PBS) and media replaced with RPMI-1640 containing $0.5 \%$ FCS without phenol red. In each experiment a light positive control without drugs (minus Photolon) and a dark control with Photolon (plus Photolon) were included. The irradiation regime involved light dose of $1 \mathrm{~J} / \mathrm{cm}^{-2}$. A portable diode laser (Ceralas PDT 665, Biolitec, USA) emitting at $665 \pm 3 \mathrm{~nm}$ was used for irradiation. The peak power output at the fiber tip was calibrated at $1.75-1.85 \mathrm{~W}$ prior to irradiation. The laser's energy was delivered to the cover of the cell culture plates/dishes via a silica fiber frontal light distributor which produced a circular spot of uniform light irradiation of 0.5$1.0 \mathrm{~cm}^{2}$ (FD model, Medlight, Switzerland). Immediately following irradiation, cell media were replaced with complete media except when otherwise specified.

\section{Confocal analyses}

Photolon subcellular localization. Intracellular distributions of Photolon were monitored under Carl Zeiss LSM510 confocal laser scanning microscope. Both mouse colon CT-26 and normal cells (NHLC) $\left(1 \times 10^{4}\right.$ cells) were seeded in 8 -well chamber slides (Nunc) in the presence of either DMEM or RPMI medium for $48 \mathrm{~h}$ at $37^{\circ} \mathrm{C}$. Then, the cells were incubated with Photolon $(10 \mu \mathrm{M} / \mathrm{ml})$ for $30 \mathrm{~min}$, washed twice with ice-cold PBS, fixed in 4\% paraformaldehyde for $15 \mathrm{~min}$, and permeablized using $0.2 \%$ Triton X-100. Following treatment with $0.1 \%$ normal goat serum for $30 \mathrm{~min}$, cells were incubated with respective organelle marker such as mitotracker, lysotracker (for mitochondrial staining, mitotracker probe was added to the live cells according to manufacturer's instructions) or with indicated primary antibodies (i.e., monoclonal Golgi antibodies 1:500 or rabbit anti-Calreticulin) for $1 \mathrm{~h}$ and subjected for PBS wash. For immunostaining, cells were further incubated with goat anti-mouse secondary antibody (Molecular Probes) tagged with AlexaFluor488 diluted at 1:400. To delineate the nuclear morphology, nuclear marker ToPro3 was used. Finally, the chambers were removed and glass slides were mounted 
with Prolong Antifade mounting agent (Molecular Probes). Both immunostained and organelle probe added cells were examined under a Zeiss AxioPlan2 (Germany) equipped with Carl Zeiss with CSM510. The objective lens (x40 magnification) through the eyepiece (x10 magnification) imaged an area of $512 \times 512 \mu \mathrm{m}$ per image. In all cases, optical sections were through the median plane of the nucleus, as determined by nuclear counterstaining. Pixel time exposure was set at $3.2 \mu \mathrm{sec}$, and $1.97 \mathrm{sec}$ was required to obtain one piece of image. Z-axis sections of the fluorescence images at nuclear positions were constructed with photomicrographs monitored approximately 20 pieces of images with a $1-\mu \mathrm{m}$ interval scanning which were sliced along direction of the Z-axis from the top to the bottom of cells; all of the sliced images were merged by using equipped LSM510 software. The fluorescence pattern of stained organelles (green fluorescence) and Photolon (though the excitation $\lambda$ of Photolon is $488 \mathrm{~nm}$ and imaging filter used was LP560) were compared. To show the extent of co-localization, green and red fluorescence (Photolon) images of the same cells were merged using LSM510 software. When Photolon and probes localize in the same organelle the fluorescence appears as yellow-orange.

Detection of cytosolic cytochrome $C$. For the determination of cytosolic cytochrome C (Cyt C), CT-26 cells $\left(2 \times 10^{3}\right)$ were grown on cover slips, treated with Photolon and subjected to light irradiation, fixed with methanol:acetone $(1: 1 \mathrm{vol} / \mathrm{vol})$ and incubated for $1 \mathrm{~h}$ at $37^{\circ} \mathrm{C}$ with 1:150 dilution (in 3\% BSA) of anti-Cyt $\mathrm{C}$ antibody (clone 7H8.2C12 Pharmingen, San Diego, CA) as described previously (14). Following three washes with $1 \mathrm{X}$ PBS $+1 \%$ FBS, cells were exposed to 1:20 dilution of anti-mouse FITC conjugated IgG (Pharmingen) for $45 \mathrm{~min}$, washed twice, and analyzed by CLSM.

Analysis of DNA fragmentation by TUNEL method. For the determination of DNA fragmentation, CT-26 cells $\left(2 \times 10^{3}\right)$ were grown on cover slips, treated with Photolon and subjected to light irradiation. At different times of post-irradiation (2-4 h), cells were subjected to TUNEL (TdT-mediated dUTP nick-end labeling) assay. Both drug treated, non-irradiated control and photoactivated tumor cells were processed according to the ApoAlert DNA fragmentation kit protocol (Clontech Laboratories, Inc., Palo Alto, CA, USA). Stained cells were examined and photographed using CCD camera attached Carl Zeiss light microscope. In a separate set of experiment, both control and irradiated cells were stained with Acridine Orange (AO) was examined under CLSM to confirm the DNA fragmentation.

\section{Flow cytometry}

Membrane phosphatidylserine (PS) translocation. Externalization of PS was assessed using the ApoAlert-Annexin V Apoptosis Kit (Clontech Laboratories). Briefly, CT-26 cells (1x10 $/ \mathrm{ml}$ ) were exposed to $10 \mu \mathrm{M} / \mathrm{ml}$ of Photolon for various times (30 min-2 h). Following exposure to Photolon, cells were gently washed with PBS $+1 \%$ FBS and resuspended in $200 \mu \mathrm{l}$ of $1 \mathrm{X}$ binding buffer (supplied by the vendor). Annexin V-FITC $(1 \mu \mathrm{g} / \mathrm{ml})$ was then added to the cells and left at room temperature for $15 \mathrm{~min}$ in the dark. Cells were washed twice with PBS, resuspended in $0.5 \mathrm{ml}$ of $\mathrm{PBS}+1 \%$ FBS and analyzed by flow cytometry with the excitation wavelength set at $488 \mathrm{~nm}$ and the emission set at $525 \mathrm{~nm}$ (green). Flow cytometry data were analyzed as described (15). Confocal scanning laser microscopy (CLSM) further verified morphologically and confirmed the above findings.

Mitochondrial membrane potential $\left(\Delta \Psi_{m}\right)$ drop. Mitochondrial transmembrane potential $\left(\Delta \Psi_{\mathrm{m}}\right)$ was studied using a $\Delta \Psi_{\mathrm{m}}$-sensitive fluorescent probe, $\operatorname{DioC}_{6}$ (3) (3,3'-dihexyloxacarbocyanine iodide; Molecular Probes). At different time intervals after Photolon-PDT, cells were collected and incubated with the $\operatorname{DioC}_{6}(3)$ solution $(40 \mathrm{~nm})$ for $10 \mathrm{~min}$, washed twice with PBS. The cells treated with the mitochondrial membrane un-coupler carbonylcyanidem-chlorophenyl hydrazone (mCICCP) for $20 \mathrm{~min}$ at $37^{\circ} \mathrm{C}$ were used as a positive control for dissipation of $\Delta \Psi_{\mathrm{m}}(16)$. Stained cells were then analyzed for their fluorescence by a FACSCalibur flow cytometer (BectonDickinson, San Jose, CA) with the excitation wavelength: $488 \mathrm{~nm}$ and emission wavelength: $500 \mathrm{~nm}$ (17).

Analysis of intracellular $\mathrm{H}_{2} \mathrm{O}_{2}$ concentration. Intracellular $\mathrm{H}_{2} \mathrm{O}_{2}$ was determined by staining with 2,7-dichlorofluorescin diacetate (DCFHDA; Molecular Probes), which is oxidized to dichlorofluorescin (DCF) by $\mathrm{H}_{2} \mathrm{O}_{2}(17,18)$. CT-26 cells were exposed to $10 \mu \mathrm{M} / \mathrm{ml}$ of Photolon for $30 \mathrm{~min}$. At different time intervals after light irradiation, cells were collected, washed with PBS and loaded with $20 \mu \mathrm{M}$ DCFHDA at $37^{\circ} \mathrm{C}$ for $30 \mathrm{~min}$, and analyzed by flow cytometry ( $\lambda$ excitation $488 \mathrm{~nm}$ ). Catalase $(1000 \mathrm{U} / \mathrm{ml})$ was used to scavenge intracellular $\mathrm{H}_{2} \mathrm{O}_{2}$ before light irradiation and flow cytometric analysis of $\mathrm{H}_{2} \mathrm{O}_{2}$. In a separate set of experiment, to assess, if Photolon-PDT induced $\mathrm{H}_{2} \mathrm{O}_{2}$ production was involved in cathepsin $\mathrm{D}$ expression, cells were incubated for 1-2 $\mathrm{h}$ with and without Catalase (1000 U/ml) prior to irradiation, followed by flow cytometry analysis for cathepsin D expression.

Analysis of cathepsin D expression. Cathepsin D expression was studied at $30 \mathrm{~min}$ to $2 \mathrm{~h}$ post-irradiation, both Photolon control and irradiated CT-26 cells were harvested subjected for flow cytometric and biochemical approach. The paraformaldehyde fixed and permeabilized cells were incubated for $1 \mathrm{~h}$ with anti-cathepsin D primary antibody (Cat no. C64020), followed by washed twice with $1 \mathrm{X}$ PBS and incubated with FITC-conjugated secondary antibody for $30 \mathrm{~min}$. A total of $10^{4}$ cells were then analyzed for their fluorescence by a FACSCalibur flow cytometer (Becton-Dickinson).

\section{Western blot analysis}

PARP cleavage. In order to confirm the involvement of caspase proteases in Photolon-PDT mediated cell death, we analyzed the cleavage of PARP in lysates of tumor cells treated with Photolon. Lysates of CT-26 cells $\left(2 \times 10^{6}\right)$ were prepared in sample buffer [62.5 mM Tris- $\mathrm{HCl}(\mathrm{pH} 6.8), 6 \mathrm{M}$ urea, $10 \%$ glycerol, 2\% SDS, $0.00125 \%$ Bromophenol Blue and $5 \% \beta$-mercaptoethanol] at different time period upon light irradiation. Following 10\% PAGE and transfer to nitrocellulose, membranes were exposed to a 1:10000 dilution of anti-PARP antibody C-2-10 made in TBS $+0.05 \%$ Tween-20 and $1 \%$ BSA at room temperature for $2 \mathrm{~h}$ or overnight. Following multiple washes with TBST, the membranes were exposed to a 1:10000 dilution of goat anti-mouse IgG-HRP conjugate supplied as 
Table I. Preparation of CT-26 cells, concentrations of Photolon and organelle-specific probes in the cell culture medium, incubation time, excitation wavelength, and the filters used for imaging in CLSM.

\begin{tabular}{llccc}
\hline Photosensitizer/probe & $\begin{array}{c}\text { Concentration } \\
\text { in medium }\end{array}$ & $\begin{array}{c}\text { Incubation } \\
\text { time (min) }\end{array}$ & $\begin{array}{c}\text { Excitation } \\
\text { wavelength (nM) }\end{array}$ & $\begin{array}{c}\text { Imaging } \\
\text { filters }\end{array}$ \\
\hline Ce6-PVP & $10 \mu \mathrm{M} / \mathrm{ml}$ & 30 & 488 & LP560 \\
Mitotracker (mitochondrial probe) & $500 \mathrm{nM} / \mathrm{ml}$ & 30 & 488 & BP505-530 \\
Lysotracker (lysosomal probe) & $500 \mathrm{nM} / \mathrm{ml}$ & 30 & 488 & BP505-530 \\
Calreticulin (endoplasmic reticulum probe; mAb) & $1: 500(1 \mu \mathrm{g} / \mathrm{ml})$ & 60 & 488 & BP505-530 \\
Golgi apparatus marker (mAb against GRASP65) & $1: 500(1 \mu \mathrm{g} / \mathrm{ml})$ & 60 & 488 & BP505-530 \\
TOPRO3 (nuclear marker) & $1 \mu \mathrm{M} / \mathrm{ml}$ & 15 & 633 & IR 565/615-661 \\
\hline
\end{tabular}

$0.8 \mathrm{mg} / \mathrm{ml}$ (Pierce, Rockford, IL) for $1 \mathrm{~h}$ and washed repeatedly with TBST. Chemiluminescence was detected using the Super Signal Substrate Western Blotting Kit (Pierce).

Cytochrome $C$ release and cathepsin $D$ expression. Wholecell samples were prepared according to a method previously described (19). In brief, following exposure to Photolon ${ }^{\mathrm{TM}}$, cells were gently washed with PBS followed by lysed in M-PER ${ }^{\circledR}$ Mammalian Protein Extraction Reagent (Pierce). Supernatants (whole cell lysates) were transferred to fresh tubes and kept at $-70^{\circ} \mathrm{C}$ until analysis. Proteins in the wholecell extracts were quantified by the Bradford method. Equal amounts of proteins from respective controls and PhotolonPDT treated cells were electrophoresed on SDS-polyacrylamide gel $(10-12 \%)$, the gel-separated proteins were transferred to polyvinylidene difluoride membranes, and the membranes were probed overnight at $4^{\circ} \mathrm{C}$ with primary antibodies. The antibodies used were as follows: mouse anti-cytochrome $\mathrm{C}$, mouse anti-cathepsin D and mouse anti-actin. After probing, the membranes were washed thrice and then incubated for $1 \mathrm{~h}$ at room temperature with the respective anti-mouse horseradish peroxidase-conjugated secondary antibodies (diluted 1:10000) before visualization by using a chemi-luminescence detection kit (Pierce).

\section{Results}

Subcellular localization of Photolon after incubation with murine colon carcinoma CT-26 and NHLC cells. Intracellular localization of Photolon in CT-26 and NHLC cells were studied using CLSM. Cells were incubated with Photolon for 15$240 \mathrm{~min}$ and subsequently observed the Photolon fluorescence. Cellular uptake of Photolon was observed as early as after 15-min incubation and was increased time-dependently up to $240 \mathrm{~min}$. Subcellular localization of the Photolon was studied using fluorescing molecular probes, which localize specifically in one cellular organelle. In general, it was found that Photolon predominantly localized in the nucleus followed by more diffused pattern in the cytoplasm, but highly accumulative especially in the nuclear periphery. However, Photolon was also detected with localization in mitochondria, lysosomes and Golgi apparatus (Table I). No fluorescence was detected in, endoplasmic reticulum whereas in NHLC cells, Photolon was found to be localized minimally only in the nucleus not in other organelles studied (data not shown). Fig. 2 show the CLSM images of representative CT-26 cells incubated with both Photolon (red fluorescence) and respective organelle specific probes (green fluorescence). The merged pictures (inset) show an orange-yellow fluorescence only if the fluorescence originates from the same organelle.

Assessment of Photolon-PDT induced apoptotic cell death. Next, we attempted to verify Photolon-PDT induced apoptotic cell death as our laboratory preliminary study (13) suggested that Photolon-PDT can induce both necrotic and apoptotic mode of cell death depending on the drug and light dose used. Apoptosis was assessed by multiple methods. The present study adhered to the recommended dose of drug $(10 \mu \mathrm{M} / \mathrm{ml})$ and light $\left(1 \mathrm{~J} / \mathrm{cm}^{-2}\right)$ in the previous study to induce apoptosis. Following light irradiation cells were incubated at $37^{\circ} \mathrm{C}$ and at different intervals of time harvested cells were subjected to different apoptosis analyses including DNA fragmentation using TUNEL assay (Fig. 3A), PS externalization (Fig. 3B, C), PARP cleavage (Fig. 3D) and observation of shrinkage in cell size by light microscopy.

Mitochondria localized Photolon and PDT associated drop in membrane potential $\left(\Delta \Psi_{m}\right)$. Mitochondrial localized photosensitizers are able to induce apoptosis very rapidly and cytochrome c release is triggered by mitochondrial depolarization following photosensitization $(15,20)$. The present study assessed the involvement of permeability transition pore (MPT) and related mechanism of cytochrome c release upon light irradiation at different time points. It is well established that the decline of $\Delta \Psi_{\mathrm{m}}$ is the result of mitochondrial swelling and rupture of outer membrane, which aids the release of cytochrome $\mathrm{c}$ from the inner membrane. Our flow cytometry results (Fig. 4A) at 15 min have shown that Photolon- PDT induced decrease in $\mathrm{DiOC}_{6}$ fluorescence intensity. $\mathrm{DiOC}_{6}$ is a known fluorescent marker to study changes in mitochondrial membrane potential. As a positive control, cells were incubated at the same time with uncoupling agent $\mathrm{mCICCP}(100 \mu \mathrm{mol} / \mathrm{l})$, a protonophore that disrupts the $\Delta \Psi_{\mathrm{m}}$. Inhibitor of MPT pore opening, such as cyclosporin A (CsA), appear to block this event (Fig. 4B) confirming that drop in $\Delta \Psi_{\mathrm{m}}$ is secondary to opening of the inner-membrane MPT pore. Besides the above, the cytochrome $\mathrm{c}$ release, a well known related event to the drop in $\Delta \Psi_{\mathrm{m}}$ was verified in this study (Fig. 4C-F). Both flow 
A

TOPRO3
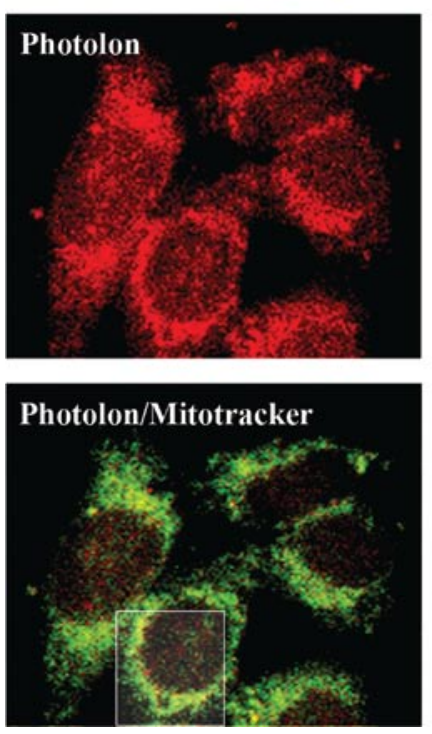

C
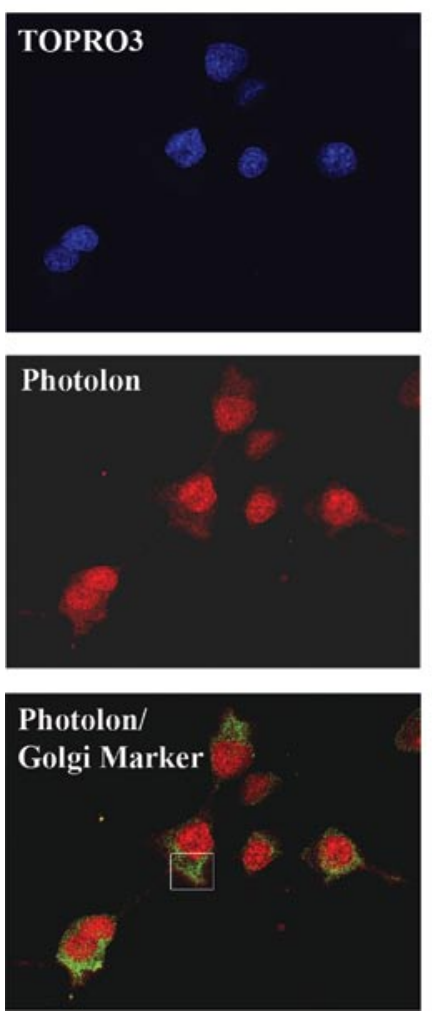
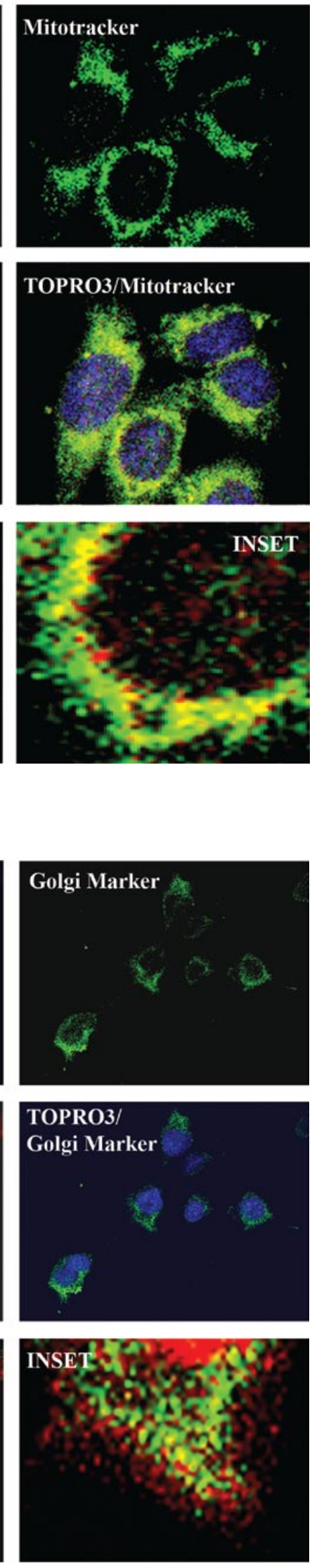

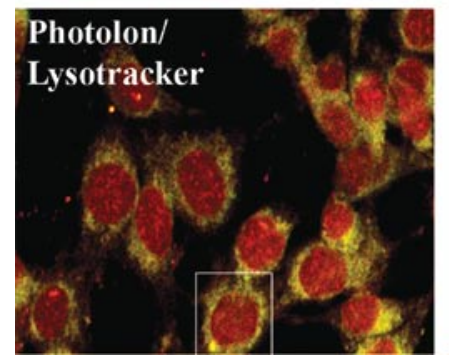

D

B
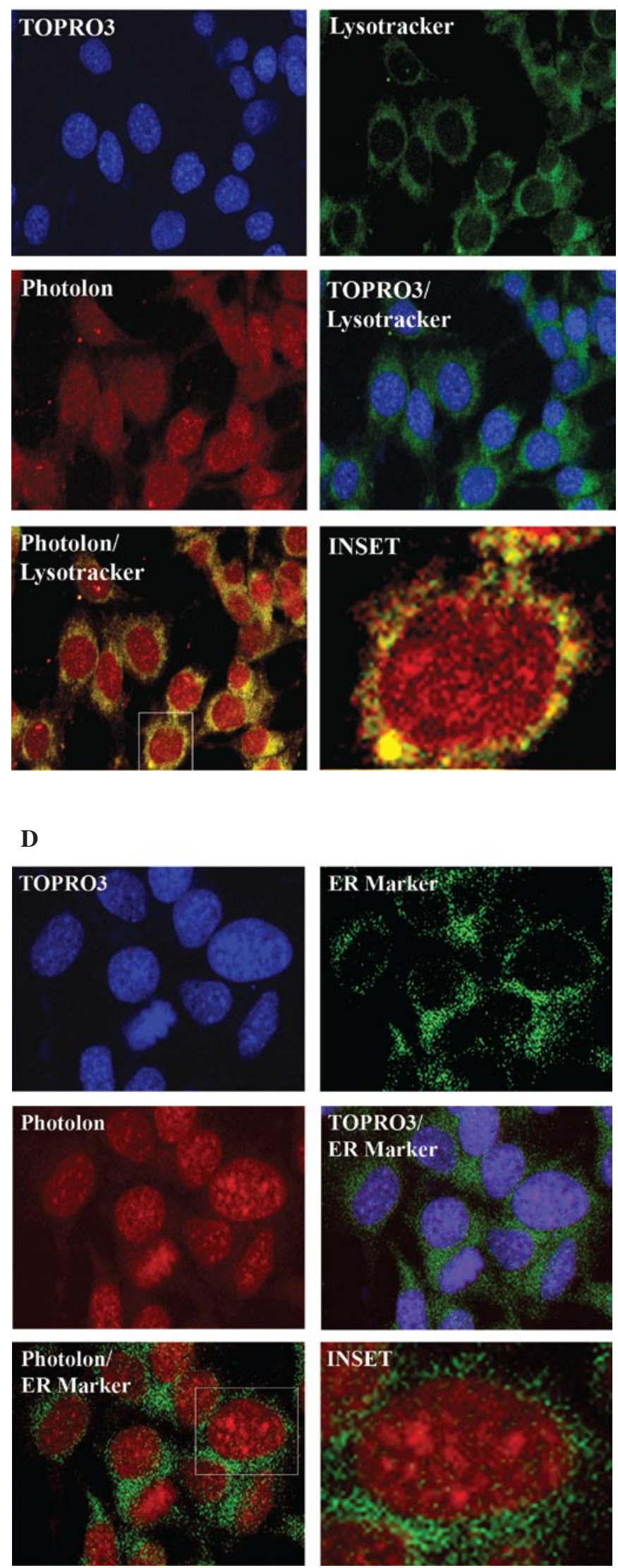

Figure 2. Intracellular localization of Photolon in CT-26 cells was characterized using CLSM. Photolon was detected with localization in mitochondria (A), lysosomes (B) and Golgi apparatus (C). No fluorescence was detected in endoplasmic reticulum (D). CLSM images of representative cells incubated with both Photolon $^{\mathrm{TM}}$ (red fluorescence) and respective organelle specific probes (green fluorescence). The merged pictures (inset) show an orange-yellow fluorescence only if the fluorescence originates from the same organelle. 
A
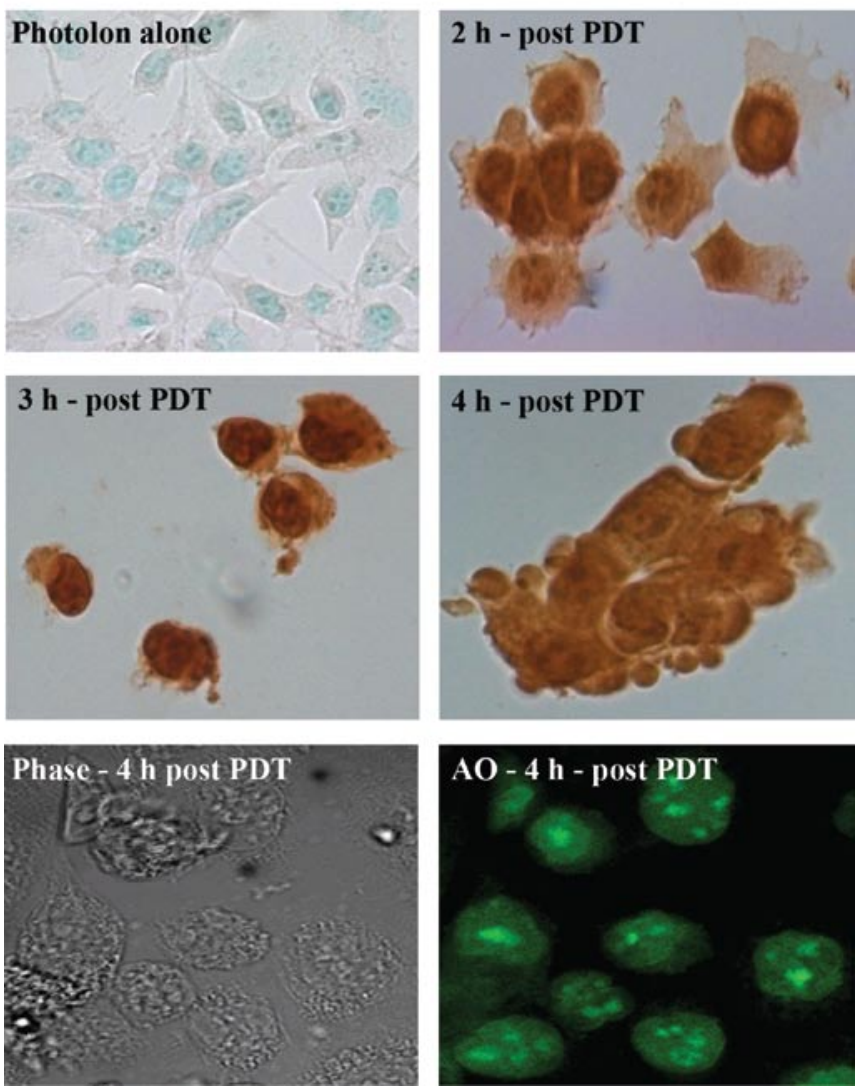

\section{C}
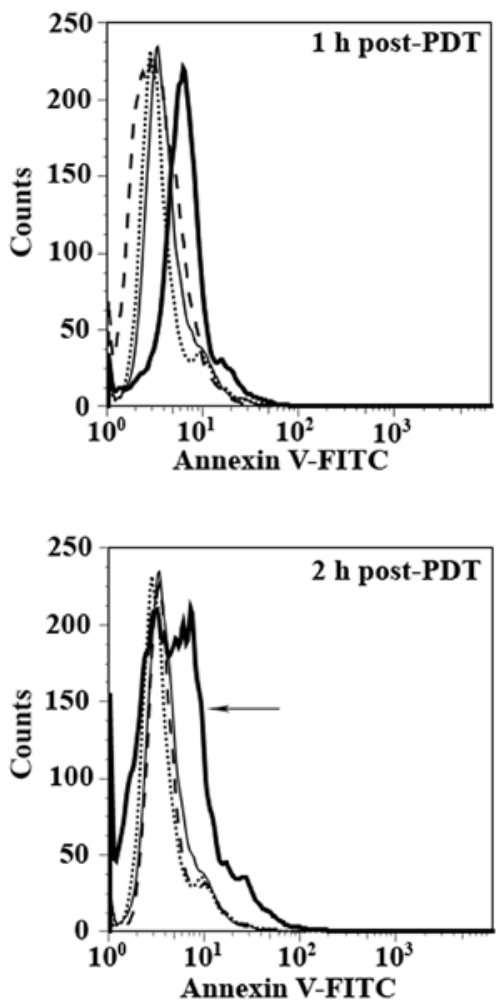

cytometric $\Delta \Psi_{\mathrm{m}}$ and cytochrome c release results confirmed that these two events were correlative and very rapid upon Photolon-PDT.

Role of lysosomal localized Photolon and PDT related events. It is well established that lysosomes contain a variety of
B
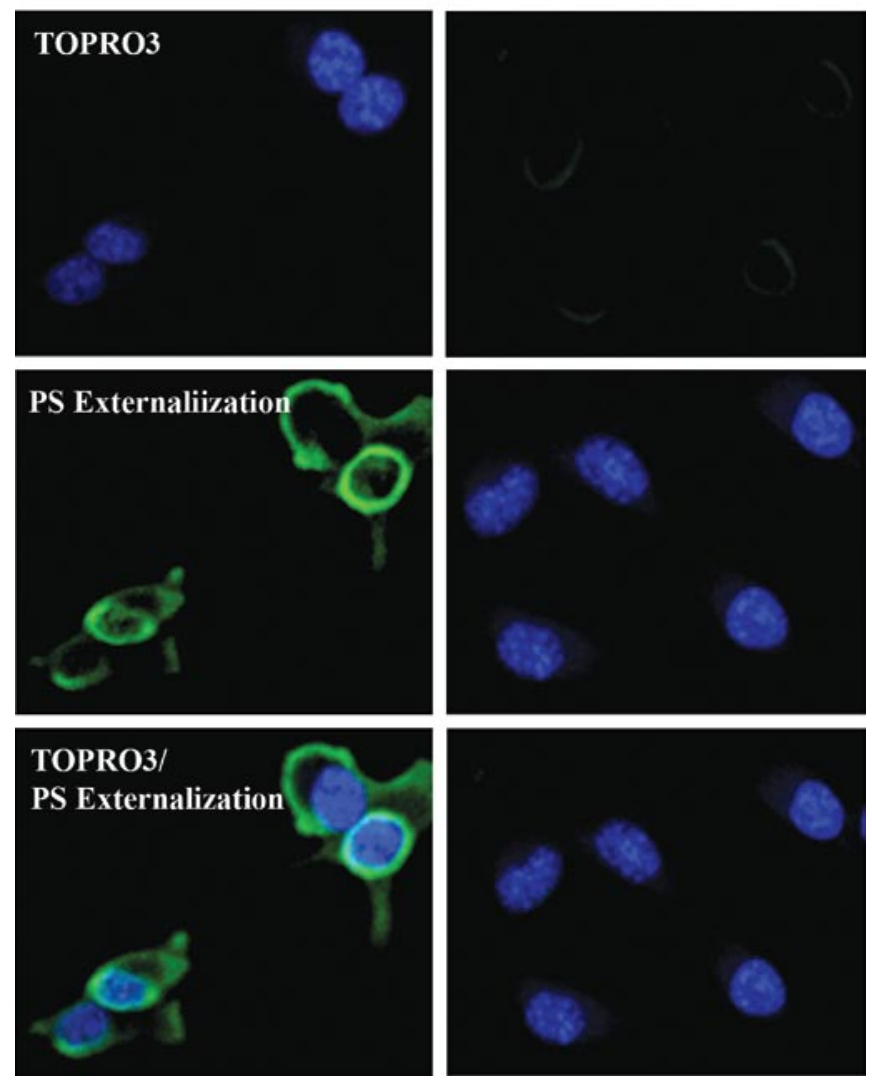

D

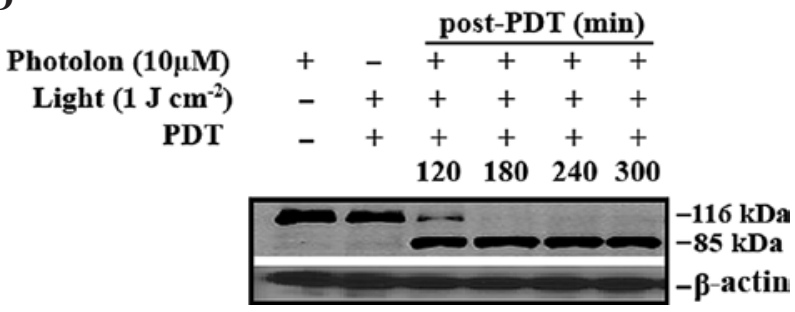

Figure 3. (A), Photolon-PDT induced changes in cell size and DNA fragmentation as compared to drug-treated non-irradiated CT-26 cells using TumorTACS In situ Apoptosis Detection Kit. Phase contrast micrograph and AO stained cells confirmed the changes in cell size and DNA fragmentation (bottom images). Cells were examined using CCD camera attached light microscope. (B), PS exposure at the external surface of the Photolon-PDT induced apoptotic cells compared to drug-treated non-irradiated control cells was assessed by the binding of FITC-labeled Annexin V. Representative images of green fluorescence indicate FITC-positive PS expressing cells as compared to control cells. (C), PS exposure at the external surface of the Photolon-PDT induced apoptotic cells compared to drug-treated non-irradiated control cells was further confirmed flow cytometry. At 1 and $2 \mathrm{~h}$ post-PDT, PS externalization was assessed in both control and irradiated CT-26 cells. At least 10000 events were analyzed using an excitation wavelength of $488 \mathrm{~nm}$ and emission set at $525 \mathrm{~nm}$. Arrow indicates FITC-positive PS expressing cells as compared to control cells. (D), SDS-PAGE analysis of PARP cleavage in whole cell lysates of Photolon-treated $(10 \mu \mathrm{M} / \mathrm{ml})$ and irradiated CT-26 cells at different post-irradiated periods. Note the intact protein of $116 \mathrm{kDa}$ and the Photolon-PDT induced proteolytic fragment of $85 \mathrm{kDa}$.

enzymes for the degradation of proteins, nucleic acids, polysaccharides, and lipids and several studies suggest that cathepsin D (Cath D) seems to have a pivotal role as a cell death mediator (21-23). In order to check whether or not the release of Cath D occurs from Photolon-PDT treated cells, we have adopted both flow cytometry and biochemical approaches 

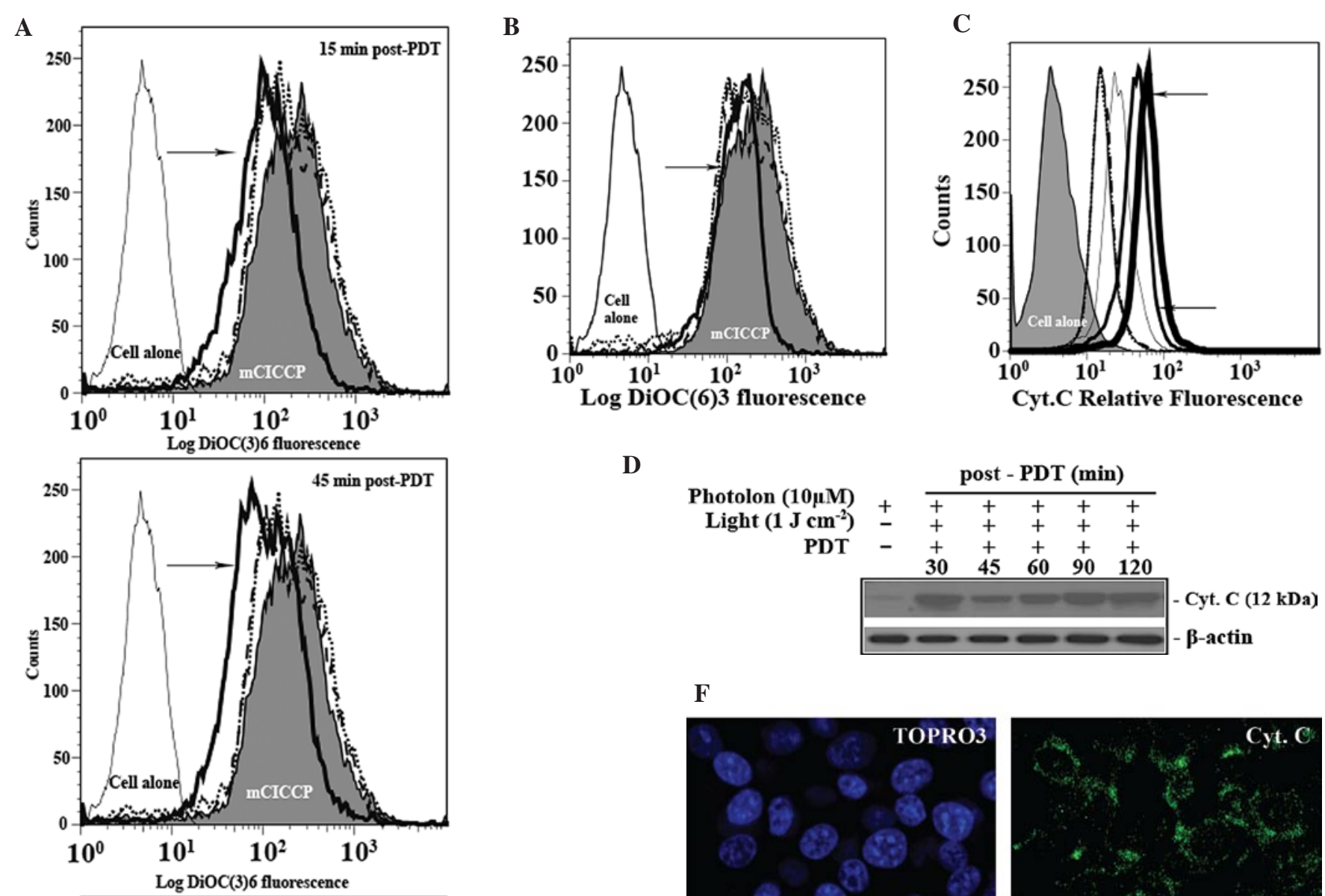

D

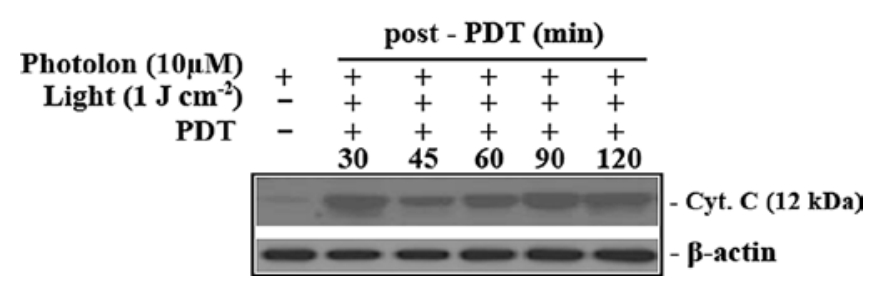

F
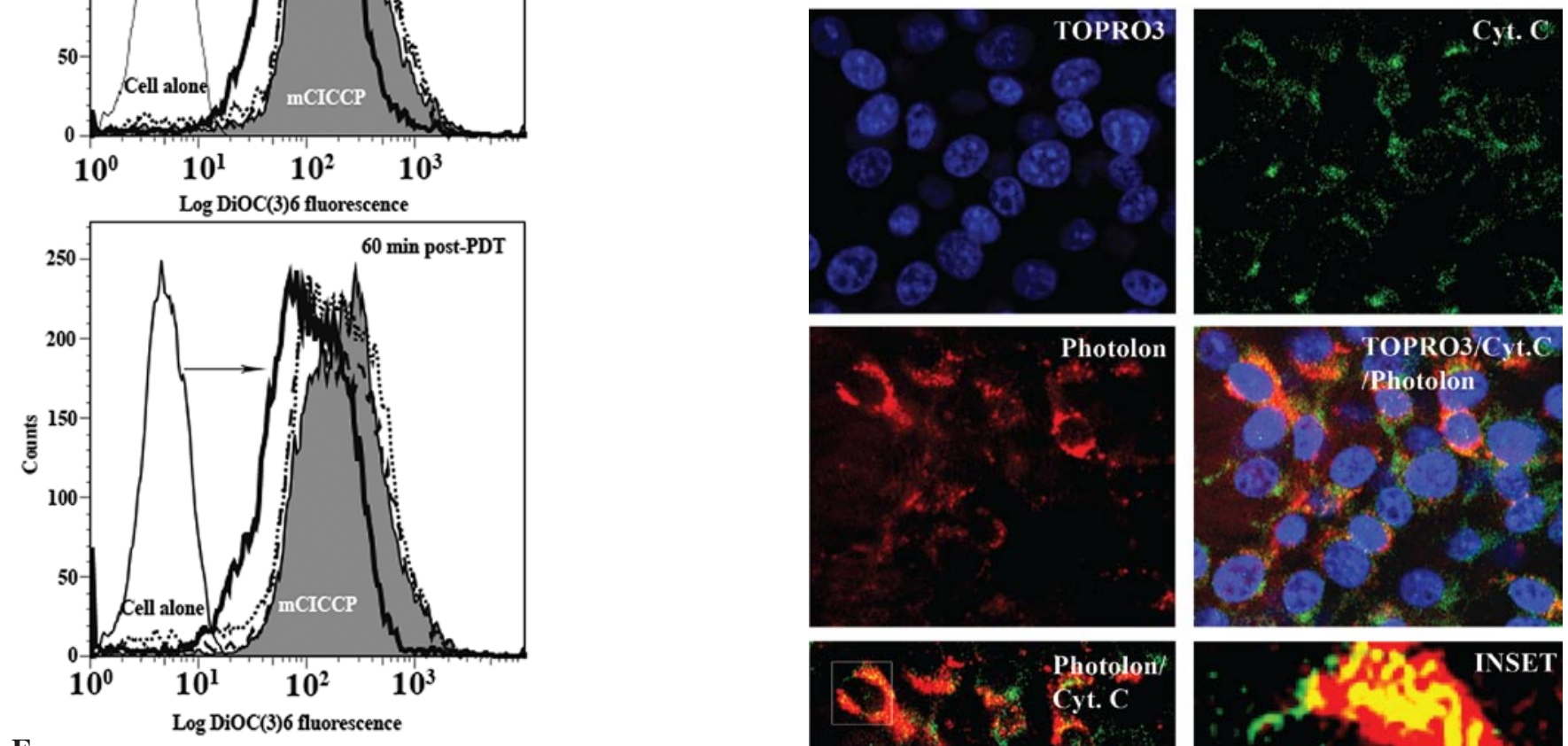

$\mathbf{E}$
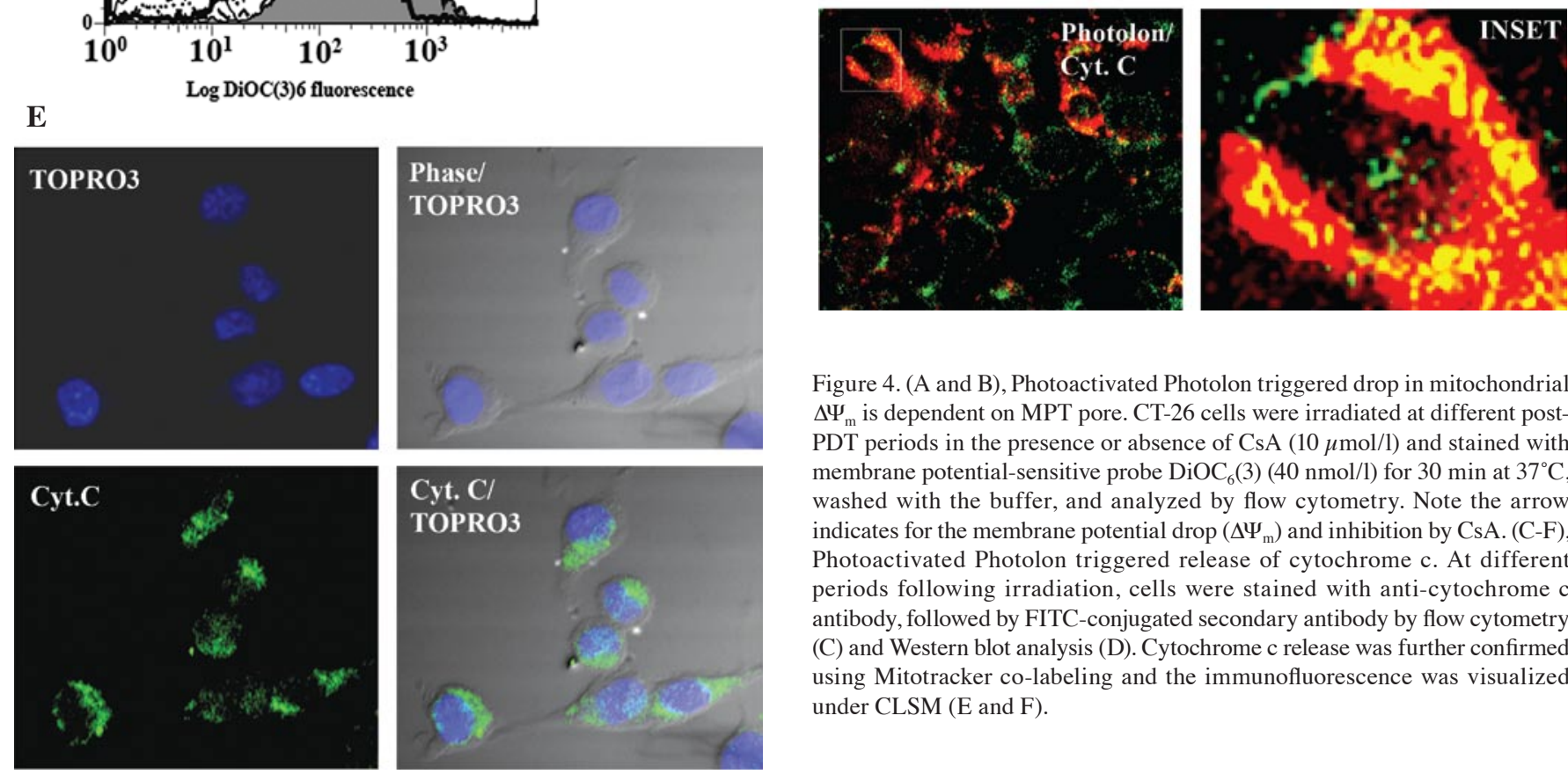

Figure 4. (A and B), Photoactivated Photolon triggered drop in mitochondrial $\Delta \Psi_{\mathrm{m}}$ is dependent on MPT pore. CT-26 cells were irradiated at different postPDT periods in the presence or absence of CsA $(10 \mu \mathrm{mol} / \mathrm{l})$ and stained with membrane potential-sensitive probe $\operatorname{DiOC}_{6}(3)(40 \mathrm{nmol} / \mathrm{l})$ for $30 \mathrm{~min}$ at $37^{\circ} \mathrm{C}$, washed with the buffer, and analyzed by flow cytometry. Note the arrow indicates for the membrane potential drop $\left(\Delta \Psi_{\mathrm{m}}\right)$ and inhibition by CsA. (C-F), Photoactivated Photolon triggered release of cytochrome c. At different periods following irradiation, cells were stained with anti-cytochrome $\mathrm{c}$ antibody, followed by FITC-conjugated secondary antibody by flow cytometry (C) and Western blot analysis (D). Cytochrome c release was further confirmed using Mitotracker co-labeling and the immunofluorescence was visualized under CLSM (E and F). 
A

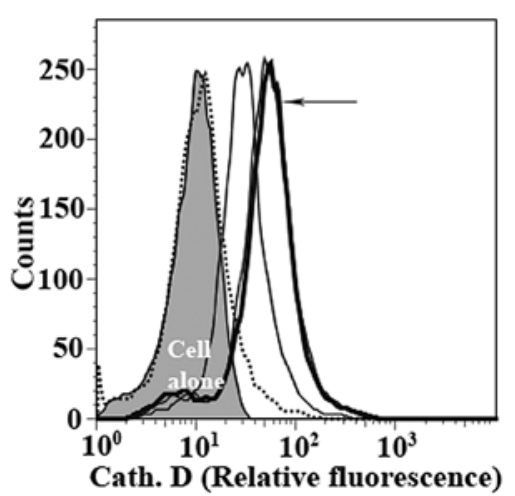

$\overline{\mathbf{B}}$

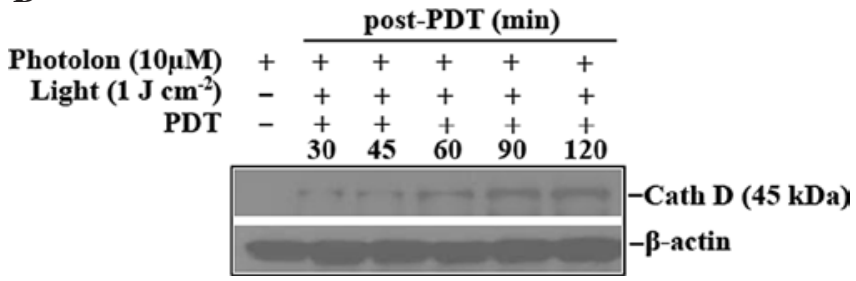

Figure 5. Photoactivated Photolon triggered release of cathepsin D. At different periods following irradiation, cells were stained with anti-cathepsin D antibody, followed by FITC-conjugated secondary antibody by two step staining method using flow cytometry (A) and Western blot analysis (B). Note cathepsin D expression was strongly increased at different post-irradiation period.

to monitor Cath D expression. Indeed, our results (Fig. 5) provide evidence for the expression of lysosomal protease Cath D that might be involved in the induction of apoptosis. To support our findings, previous studies have shown that lysosomal localized photosensitizers can induce both necrosis and apoptosis $(15,24,25)$.

Photolon-PDT induced $\mathrm{H}_{2} \mathrm{O}_{2}$ production. The biological effect of PDT depends on singlet oxygen or other oxygen species induced cell death $(15,26,27)$ and our results have supported the hypothesis of mitochondria and lysosomal based photodynamic anti-cancer therapy (28). Therefore, the present study aimed to determine whether ROS production is involved in Photolon-PDT induced apoptosis. In this regard, $\mathrm{H}_{2} \mathrm{O}_{2}$ was chosen because $\mathrm{H}_{2} \mathrm{O}_{2}$ was implicated in PDT-mediated cell death $(15,29)$. DCFH-DA was used to detect the amount of intracellular $\mathrm{H}_{2} \mathrm{O}_{2}$. The content of $\mathrm{H}_{2} \mathrm{O}_{2}$ in the Photolon-PDT treated cells was gradually increased from 30-45 min and peaked at $1 \mathrm{~h}$ post-irradiation (Fig. 6) followed by decline at $3 \mathrm{~h}$. In order to confirm that the $\mathrm{H}_{2} \mathrm{O}_{2}$ production is indeed specific, the present study used Catalase, a selective scavenger of $\mathrm{H}_{2} \mathrm{O}_{2}$ to inhibit its production. Indeed, our flow cytometric results provide evidence that photosensitization of Photolon results in the generation of $\mathrm{H}_{2} \mathrm{O}_{2}$.

Possible role of $\mathrm{H}_{2} \mathrm{O}_{2}$ for the expression cathepsin D. Localization of chlorin in lysosomes has been reported and several mechanisms of photosensitization were proposed $(30,31)$. Photolon as a chlorin and localized in lysosomes like other chlorin photosensitizers and involved in $\mathrm{H}_{2} \mathrm{O}_{2}$ production, thus, we aimed at investigating the possible role of $\mathrm{H}_{2} \mathrm{O}_{2}$ for the expression of cathepsin $\mathrm{D}$ as previous studies have shown
A
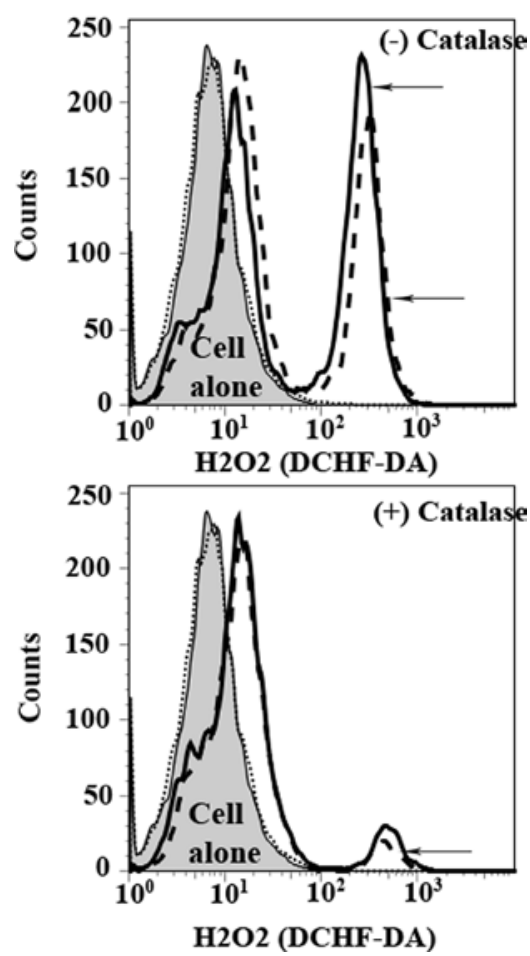

Figure 6. Involvement of $\mathrm{H}_{2} \mathrm{O}_{2}$ production in the Photolon-PDT treated CT-26 cells were analyzed by flow cytometry. DCFH-DA was used to detect the amount of intracellular $\mathrm{H}_{2} \mathrm{O}_{2}$. The content of $\mathrm{H}_{2} \mathrm{O}_{2}$ in the Photolon-PDT treated cells was gradually increased from 30 to 45 min and peaked at $1 \mathrm{~h}$ post-irradiation followed by decline at $3 \mathrm{~h}$ (A). In order to confirm the $\mathrm{H}_{2} \mathrm{O}_{2}$ production is indeed specific, the present study used Catalase, a selective scavenger of $\mathrm{H}_{2} \mathrm{O}_{2}$ to inhibit its production (B). Note the arrow indicates both the $\mathrm{H}_{2} \mathrm{O}_{2}$ production and inhibition by Catalase compared to Photolon-treated, non-irradiated control cells

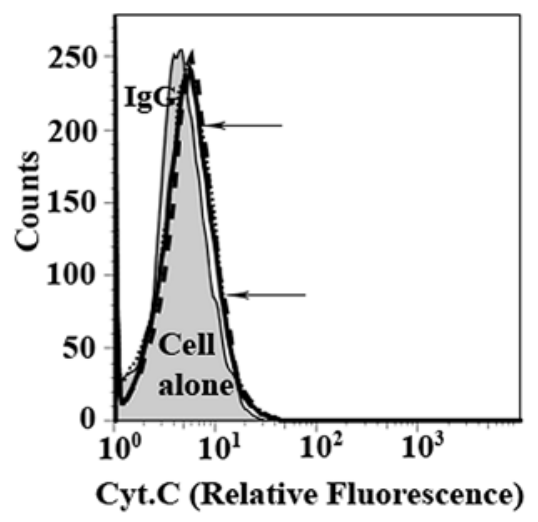

Figure 7. Possible involvement of $\mathrm{H}_{2} \mathrm{O}_{2}$ for cathesin D expression was verified using flow cytometry analysis. In order to confirm the $\mathrm{H}_{2} \mathrm{O}_{2}$ involvement is indeed specific, the present study used Catalase, a selective scavenger of $\mathrm{H}_{2} \mathrm{O}_{2}$ to inhibit its production and to see the cathepsin D expression indirectly. Note, Photolon-PDT induced cathepsin D expression was inhibited when compared to the results seen in Fig. 5A.

that $\mathrm{H}_{2} \mathrm{O}_{2}$ treatment caused apoptosis $(15,32)$ and involved cathepsin D expression (15,33,34). Our results (Fig. 7) using $\mathrm{H}_{2} \mathrm{O}_{2}$ inhibition approach by $\mathrm{H}_{2} \mathrm{O}_{2}$ scavengers confirmed the previous findings and suggestions that $\mathrm{H}_{2} \mathrm{O}_{2}$ is indeed involved in the cathepsin D expression. 


\section{Discussion}

PDT is a novel treatment for cancer and certain non-malignant conditions, which employs a photosensitive drug followed by light in the visible range to produce an oxidative stress and cell death in the targeted tissue. The PS, that localize in one or more intracellular membranes and that are activated by longwavelength (red) visible light. Singlet molecular oxygen $(35,36)$ and other reactive oxygen species $(15,27)$ are the primary damaging species produced by PDT, and these oxidize cellular substrates, including lipids and proteins of the membranes in which the PS resides (37). The continuing positive and encouraging clinical results associated with PDT $(38,39)$ have led to an expanded need to identify the cellular targets and molecular responses associated with this treatment. Increased knowledge regarding the mechanisms of action associated with PDT-mediated cytotoxicity should contribute to the continued advancement of this therapy. Since PS localization has been shown to affect the mode of photodamage, the present study was carried out to identify subcellular targets and cellular responses associated with Photolon. Here we provide evidence for the cellular fluorescence localization of Photolon using CLSM. Co-labeling with Photolon and fluorescent dyes specific for cell organelles revealed an intracellular localization of Photolon predominantly in nucleus, mitochondria, lysosomes and minimally in the Golgi apparatus.

PDT is an efficient inducer of apoptosis; this has been demonstrated in many cell types and with many different PSs. The identification of primary photodamage sites can be done by measuring the activities of proteins, typical of subcellular organelles immediately after irradiation. Once induced, apoptosis follows recognized paths, it is now recognized that damage to certain subcellular structures is correlated to a specific cell death mechanism. In a series of studies by others $(12,30)$ and our laboratory (15-17) have shown that photosensitizers that localize in mitochondria are very efficient inducers of apoptosis and cytochrome c release is one of the best known apoptotic events after photosensitization $(15,20,40)$ followed by activated caspases and resulting in DNA fragmentation and morphological apoptosis.

ROS act as a second messenger in cell signaling and are essential for various biological processes including cell death. ROS production is a mechanism shared by all non-surgical therapeutic approaches for cancers, including chemotherapy, radiotherapy and PDT. Mitochondria can be a source of ROS and a target of oxidative damage during oxidative stress (41). Previous studies have shown that ROS induce mitochondrial depolarization and release of cytochrome c during phthalocyanine 4 and hypericin-PDT $(42,43)$. Our results demonstrate a reduction in mitochondrial potential in Photolon-treated CT-26 cells, suggesting that Photolon-PDT may also produce ROS which are critical to the induction of apoptosis, which may induce mitochondrial depolarization and release cytochrome c. The present study evidenced the type of ROS produced after Photolon-PDT is $\mathrm{H}_{2} \mathrm{O}_{2}$ but we cannot rule out the possibility for other free radical species involvement so this mechanism is yet to be addressed.

Localization of chlorin in lysosomes was previously reported and several mechanisms of photosensitization were proposed $(30,44)$. Photolon localized in the lysosomes like other chlorin photosensitizers, it is obvious to think that the cell death after irradiation occurs also through lysosome destruction in conjuction with mitochondrial pathway. The evaluation of lysosomal photosensitization is difficult because sensitizers that localize in lysosomes can cause cell death via two mechanisms: release of lysosomal enzymes in the cytosol or re-localization of the sensitizer, before or during illumination, to other non-lysosomal targets $(24,45)$. The proposed pathway of apoptosis induction after lysosomal photosensitization includes the release of cathepsin D, cleavage of the pro-apoptotic protein Bid which promotes the loss of mitochondrial membrane potential and the release of cyto-chrome c (46-48). This apoptotic pathway occurs between 0.5 and $2 \mathrm{~h}$ (49) and is slower than immediate apoptosis caused by direct mitochondrial photosensitization $(17,50)$. In the case of the studied Photolon, apoptosis could be detected 1-2 $\mathrm{h}$ after activation, which is in accordance with a lysosomes photodamage and apoptosis induction through release of cathepsins.

While many photosensitizing agents in current clinical use have mitochondrial targets, Photolon may be a valuable addition to current protocols. In addition, our results also indicate that leakage of lysosomal protease cathepsin D into cytosolic compartment might be involved in the induction of apoptosis. Both biochemical and flow cytometry evidence revealed damage to cells resulted in induction of apoptosis indicated by typical morphological signs of apoptosis. Despite extensive studies on how different PS incorporation and sub-cellular localization and related mode of photodamage occurs in vitro and in vivo, the specific signaling mechanism responsible for Photolon-mediated cell death and related clinical success still remains unsolved.

Besides the above, it is well known that porphyrins such as chlorin e6 and hematoporphyrin derivatives localize largely at the plasma membrane (51), it is also known that intracellular sites, and particularly the nucleus, are much more sensitive sites for photodynamic damage (51-53). Consistent and support to this; our present results indicate that the direct nuclear localization of Photolon with the appropriate light dose may enhance the ability of photosensitization. Photolon localization, particularly at sensitive subcellular organelles including the nucleus with other organelles discussed here would seem to be a key to performing efficient photodynamic therapy but future work is indeed needed to specifically address the nuclear localization.

In conclusion, our results based on Photolon localization in the cellular organelles including mitochondria and lysosome support the idea that PDT can contribute to elimination of malignant cells by the induction of apoptosis, and can be of physiological significance. Our results are in strong agreement with others that the incorporation and sub-cellular localization of photosensitizers are critical determinants of their efficiency.

\section{Acknowledgements}

We thank National Cancer Centre Singapore (NCCS) Research Foundation for providing funds to carry out the entire work reported here. 


\section{References}

1. Dougherty TJ: Photodynamic therapy. Photochem Photobiol 58: 895-900, 1993.

2. Dougherty TJ, Gomer CJ, Henderson BW, Jori G, Kessel D, Korbelik M, Moan J and Peng Q: Photodynamic therapy. J Natl Cancer Inst 90: 889-905, 1998 .

3. Reynolds T: Photodynamic therapy expands its horizons. J Natl Cancer Inst 89: 112-114, 1997.

4. Rowe PM: Photodynamic therapy begins to shine. Lancet 351 1496, 1998 .

5. Kostenich GA, Zhuravkin IN and Zhavrid EA: Experimental grounds for using chlorin e6 in the photodynamic therapy of malignant tumors. J Photochem Photobiol B 22: 211-217, 1994.

6. Lukyanov AN and Torchilin VP: Micelles from lipid derivatives of water-soluble polymers as delivery systems for poorly soluble drugs. Adv Drug Deliv Rev 56: 1273-1289, 2004.

7. Kaneda Y, Tsutsumi Y, Yoshioka Y, Kamada H, Yamamoto Y, Kodaira H, Tsunoda S, Okamoto T, Mukai Y, Shibata H, Nakagawa S and Mayumi T: The use of PVP as a polymeric carrier to improve the plasma half-life of drugs. Biomaterials 25: 3259-3266, 2004.

8. Isakau HA, Parkhats MV, Knyukshto VN, Dzhagarov BM, Petrov EP and Petrov PT: Toward understanding the high PDT efficacy of chlorin e6-polyvinylpyrrolidone formulations: photophysical and molecular aspects of photosensitizer-polymer interaction in vitro. J Photochem Photobiol B 92: 165-174 2008.

9. Shliakhtsin SV, Trukhachova TV, Isakau HA and Istomin YP: Pharmacokinetics and biodistribution of Photolon (Fotolon) in intact and tumor-bearing rats. Photodiagnosis Photodyn Ther 6 : 97-104, 2009

10. Calzavara-Pinton PG, Venturini M and Sala R: Photodynamic therapy: update 2006. Part 1: Photochemistry and photobiology. J Eur Acad Dermatol Venereol 21: 293-302, 2007.

11. Kessel D and Woodburn K: Bio-distribution of photosensitizing agents (Review). Int J Biochem 25: 1377-1383, 1993.

12. Luo Y and Kessel D: Initiation of apoptosis versus necrosis by photodynamic therapy with chloroaluminum phthalocyanine (Review). Photochem Photobiol 66: 479-483, 1997.

13. Chin WW, Heng PW, Thong PS, Bhuvaneswari R, Kuenzel HWS Soo KS and Olivo M: Improved formulation of photosensitizer chlorin e6 polyvinylpyrrolidone for fluorescence diagnostic imaging and photodynamic therapy of human cancer. Eur J Pharm Biopharm 69: 1083-1093, 2008.

14. Pervaiz S, Seyed MA, Hirpara JL, Clement MV and Loh KW: Purified photoproducts of merocyanine 540 trigger cytochrome C release and caspase 8 -dependent apoptosis in human leukemia and melanoma cells. Blood 93: 4096-4108, 1999.

15. Ali SM, Chee SK, Yuen GY and Olivo M: Hypocrellins and Hypericin induced apoptosis in human tumor cells: a possible role of hydrogen peroxide. Int J Mol Med 9: 461-472, 2002.

16. Nutku E, Hudson SA and Bochner BS: Mechanism of Siglec-8 induced human eosinophil apoptosis: role of caspases and mitochondrial injury. Biochem Biophys Res Commun 336 918-924, 2005.

17. Ali SM and Olivo M: Bio-distribution and subcellular localization of hypericin and its role in PDT induces apoptosis in cancer cells Int J Oncol 21: 531-540, 2002.

18. Possel H, Noack N, Augustin W, Keilhoff G and Wolf G: 2,7-Dihydrodichlorofluorescein diacetate as a fluorescent marker for peroxynitrite formation. FEBS Lett 416: 175-178, 1997.

19. Strømhaug PE, Berg TO, Fengsrud M and Seglen PO: Purification and characterization of autophagosomes from rat hepatocytes. Biochem J 335: 217-224, 1998.

20. Granville DJ, Carthy CM, Jiang H, Shore GC, McManus BM and Hunt DW: Rapid cytochrome c release, activation of caspases 3 6,7 and 8 followed by Bap31 cleavage in HeLa cells treated with photodynamic therapy. FEBS Lett 437: 5-10, 1998.

21. Leist and Jaattela M: Triggering of apoptosis by cathepsins. Cell Death Differ 8: 324-326, 2001.

22. Salvesen A: Lysosomal protease enters the death scene. J Clin Invest 107: 21-22, 2001.

23. Jaattela M,Cande C and Kroemer G: Lysosomes and mitochondria in the commitment to apoptosis: a potential role for cathepsin D and AIF. Cell Death Differ 11: 135-136, 2004.

24. Berg K and Moan J: Lysosomes and microtubules as targets for photochemotherapy of cancer. Photochem Photobiol 65: 403-409, 1997.
25. Noodt BB, Berg K, Stokke T, Peng Q and Nesland JM: Different apoptotic pathways are induced from various intracellular sites by tetraphenylporphyrins and light. Br J Cancer 79: 72-81, 1999.

26. Kennedy JC, Pottier RH and Pross DC: Photodynamic therapy with endogenous protoporphyrin IX: basic principles and present clinical experience. J Photochem Photobiol B 6: 143-148, 1990.

27. Ali SM and Olivo M: Nitric oxide mediated photo-induced cell death in human malignant cells. Int J Oncol 22: 751-756, 2003.

28. Morgan J and Oseroff AR: Mitochondria-based photodynamic anti-cancer therapy. Adv Drug Deliv Rev 49: 71-86, 2001.

29. Sakharov DV, Bunschoten $A$, van Weelden $H$ and Wirtz KW: Photodynamic treatment and $\mathrm{H}_{2} \mathrm{O}_{2}$-induced oxidative stress result in different patterns of cellular protein oxidation. Eur J Biochem 270: 4859-4865, 2003

30. Kessel D, Woodburn K, Gomer GJ, Jagerovic N and Smith KM: Photosensitization with derivatives of chlorin p6. J Photochem Photobiol B 28: 13-18, 1995.

31. Lee CC,Pouge BW, Strawbridge RR, Moodie KL, Bartholomew LR, Burke GC and Hoopes PJ: Comparison of photosensitizer (AIPcS2) quantification techniques: in situ fluorescence microsampling versus tissue chemical extraction. Photochem Photobiol 74: 453-460, 2001

32. Gardner AM, Xu FH, Fady C, Jacoby FJ, Duffey DC, Tu Y and Lichtenstein A: Apoptotic vs. non-apoptotic cytotoxicity induced by hydrogen peroxide. Free Radic Biol Med 22: 73-83, 1997.

33. Yin L, Stearns R and González-Flecha B: Lysosomal and mitochondrial pathways in $\mathrm{H}_{2} \mathrm{O}_{2}$-induced apoptosis of alveolar type II cells. J Cell Biochem 94: 433-445, 2005.

34. Lee DC, Mason CW, Goodman CB, Holder MS, Kirksey OW, Womble TA, Severs WB and Palm DE: Hydrogen peroxide induces lysosomal protease alterations in PC12 cells. Neurochem Res 32: 1499-1510, 2007.

35. Valenzeno D: Photomodification of biological membranes with emphasis on singlet oxygen mechanisms. Photochem Photobiol 46: 146-160, 1987.

36. Nonell in S, Jori G, Pottier RH, Rodgers MAJ and Truscott TG (eds): Photobiology in Medicine. Plenum Press, New York, NY, p29, 1994.

37. Peng Q, Moan J and Nesland JM: Correlation of subcellular localization and intratumoral photosensitizer localization with ultrastructural features after photodynamic therapy. Ultrastruct Pathol 20: 109-129, 1996.

38. Thong PS, Ong KW, Goh NS, Kho KW, Manivasager V, Bhuvaneswari R, Olivo M and Soo KC: Photodynamic-therapyactivated immune response against distant untreated tumors in recurrent angiosarcoma. Lancet Oncol 8: 950-952, 2007.

39. Winters U, Daayana S, Lear JT, Tomlinson AE, Elkord E, Stern PL and Kitchener HC: Clinical and immunologic results of a phase II trial of sequential imiquimod and photodynamic therapy for vulval intraepithelial neoplasia. Clin Cancer Res 14: 5292-5299, 2008.

40. Oleinick NL, Morris RL and Belichenko I: The role of apoptosis in response to photodynamic therapy: what, where, why, and how. Photochem Photobiol Sci 1: 1-2, 2002.

41. Kowaltowski AJ, De Souza-Pinto NC, Castilho RF and Vercesi AE: Mitochondria and reactive oxygen species. Free Radic Biol Med 47: 333-343, 2009.

42. Kessel D and Luo Y: Photodynamic therapy: a mitochondrial inducer of apoptosis. Cell Death Differ 6: 28-35, 1999.

43. Lam M, Oleinick NL and Nieminen AL: Photodynamic therapy induced apoptosis in epidermoid carcinoma cells. Reactive oxygen species and mitochondrial inner membrane permeabilization. J Biol Chem 276: 47379-47386, 2001.

44. Pouge B, Ortel B, Chen N, Redmond R and Hasan T: A photobiological and photophysical-based study of phototoxicity of two chlorines. Cancer Res 6: 717-724, 2001.

45. Gèze M, Morlière P, Mazière JC, Smith KM and Santus R: Lysosomes, a key of hydrophobic photosensitizers proposed for photochemotherapeutic applications. J Photochem Photobiol B 20: 23-35, 1993.

46. Kessel D, Luo Y, Mathieu P and Reiners JJ Jr: Determinants of the apoptotic response to lysosomal photodamage. Photochem Photobiol 71: 196-200, 2000.

47. Reiners JJ Jr, Caruso JA, Mathieu P, Chelladurai B, Yin XM and Kessel D: Release of cytochrome c and activation of pro-caspase-9 following lysosomal photodamage involves Bid cleavage. Cell Death Differ 9: 934-944, 2002. 
48. Blomgran R, Zheng L and Stendahl O: Cathepsin-cleaved Bid promotes apoptosis in human neutrophils via oxidative stressinduced lysosomal membrane permeabilization. J Leukoc Biol 81: 1213-1223, 2007

49. Godar DE: Light and death: photons and apoptosis. J Invest Dermatol 4: 17-23, 1999.

50. Li R, Bounds DJ, Granville D, Ip SH, Jiang H, Margaron P and Hunt DW: Rapid induction of apoptosis in human keratinocytes with the photosensitizer QLT0074 via a direct mitochondrial action. Apoptosis 8: 269-275, 2003.
51. Roberts WG and Berns MW: In vitro photosensitization I. Cellular uptake and subcellular localization of mono-L-aspartyl chlorin e6, chloro-aluminum sulfonated phthalocyanine, and photofrin II. Lasers Surg Med 9: 90-101, 1989.

52. Alper T: Cellular Radiobiology. Cambridge University Press, Cambridge, 1979.

53. Yano T, Takahashi S and Ichikawa T: Active oxygen generated in the process of carcinogen metabolism can induce oxidative damage in nuclei. Res Commun Mol Pathol Pharmacol 87: 367-370, 1995. 